\title{
Effect of Alpha-tocopherol on Restenosis after Angioplasty in a Model of Experimental Atherosclerosis
}

\author{
Antoine M. Lafont, ${ }^{\star \star \S}$ Yuh-Cherng Chai, ${ }^{\star}$ J. Fredrick Cornhill, ${ }^{\S}$ Patrick L. Whitlow, ${ }^{\ddagger}$ Philip H. Howe, ${ }^{\star}$ and Guy M. Chisolm \\ ${ }^{*}$ Departments of Cell Biology, ${ }^{\ddagger}$ Cardiology, and ${ }^{\S}$ Biomedical Engineering, Research Institute, Cleveland Clinic Foundation, Cleveland, \\ Ohio 44195
}

\begin{abstract}
The ability of alpha-tocopherol to reduce restenosis after angioplasty was tested in a rabbit model in which angioplasty was performed on established atherosclerotic lesions. Lesions induced by 4 wk of cholesterol feeding after focal desiccation of femoral arteries were balloon dilated. 3 wk after angioplasty, angiographically determined minimum luminal diameters were less in the untreated group $(0.80 \pm 0.51 \mathrm{~mm})$ than in the group treated with oral alphatocopherol beginning $19 \mathrm{~d}$ before angioplasty $(1.38 \pm 0.29$ $\mathrm{mm} ; \boldsymbol{P}<0.01)$. The cross-sectional area of the intima-media was greater in the untreated group $\left(1.18 \pm 0.48 \mathrm{~mm}^{2}\right)$ than in the alpha-tocopherol group $\left(0.62 \pm 0.25 \mathrm{~mm}^{2}, P<0.0001\right)$. These differences were not due to vasoconstriction or altered plasma cholesterol. Alpha-tocopherol thus reduced restenosis after angioplasty in this model. In rabbit vascular smooth muscle cells, oxidized low density lipoprotein stimulated DNA synthesis. Alpha-tocopherol treatment inhibited DNA synthesis stimulated by oxidized low density lipoprotein, but not by serum. The findings are consistent with the hypothesis that oxidized lipids can stimulate hyperplasia and that antioxidants may limit hyperplasia by inhibiting either the oxidation or the proliferative effects of oxidants on cells. $(J$. Clin. Invest. 1995. 95:1018-1025.) Key words: lipid peroxidation • low density lipoprotein • rabbit • vascular smooth muscle cells
\end{abstract}

\section{Introduction}

Angioplasty is a widely used, well-accepted treatment of stenotic lesions resulting from atherosclerosis; however, its benefits in humans are compromised by a $30-40 \%$ restenosis rate in coronary arteries. Restenosis is believed by many to be largely the result of intimal smooth muscle cell (SMC) ${ }^{1}$ prolif-

Address correspondence to Dr. Guy M. Chisolm, Department of Cell Biology, The Cleveland Clinic Foundation, NC10, 9500 Euclid Avenue, Cleveland, OH 44195. Phone: 216-444-5854; FAX: 216-444-9404. Dr. Lafont's current address is Assistance Publique Hôpitaux de Paris, Hôpital Boucicaut, Service de Cardiologie, 78, Rue de la Convention, 75730 Paris Cedex 15, France.

Received for publication 5 November 1993 and in revised form 24 October 1994.

1. Abbreviations used in this paper: EEL, external elastic lamina; MLD, minimum luminal diameter; SMC, smooth muscle cells.

J. Clin. Invest.

(C) The American Society for Clinical Investigation, Inc.

0021-9738/95/03/1018/08 \$2.00

Volume 95, March 1995, 1018-1025 eration $(1,2)$, and growth factors are believed to be influential; however, it remains unclear which growth promoting and growth inhibiting actions dominate in injured arteries of experimental animals and humans.

It is increasingly clear that atherosclerotic lesions in humans and experimental animal models contain oxidized lipids and lipoproteins (3-5). Balloon injury may invite the increased availability of lipid substrate for oxidation by allowing enhanced entry of macromolecules like lipoproteins past the damaged endothelium and internal elastic lamina (6). It may also increase the opportunity for further lipid and lipoprotein oxidation by reactive oxygen species produced either during the arterial wall ischemia induced by balloon inflation or after the balloon injury by inflammatory cells known to invade the injury site and known to produce reactive oxygen species. It is therefore possible that oxidants or lipid and lipoprotein oxidation products present in the preexisting lesion, as well as those formed in response to balloon injury, could influence the restenosis process.

Available data from in vitro studies provide an apparent contradiction regarding the potential roles of oxidized lipids and lipoproteins in cell proliferation. Under certain circumstances oxidative stress can enhance cell proliferation $(7,8)$. Diabetes is one of the strongest risk factors for restenosis (9), and circulating oxidized lipids and lipoproteins have been detected both in diabetic animals and in humans (10). In contrast, at higher concentrations, lipid peroxidation products and oxidized lipoproteins are also known to injure proliferating cells $(11,12)$. Lipid peroxidation products and oxidized lipoproteins have thus been shown in cell culture to have both negative and positive effects on cell proliferation, both by direct actions and by indirect influences on growth factor production. We believe that these oxidants and lipid oxidation products could readily influence SMC growth in vivo, and we hypothesize that in the context of a balloon-injured artery these agents promote restenosis.

Published reports on the effects of alpha-tocopherol on SMC proliferation also present curious discrepancies. Alpha-tocopherol has been shown to inhibit SMC proliferation in culture (13) by some researchers, but others have shown SMC proliferation enhancement by alpha-tocopherol (14).

As a step toward evaluating the roles of these oxidants and oxidation products in restenosis after angioplasty, we chose to examine the effects of oral pretreatment with alpha-tocopherol. Because our hypothesis proposes a restenosis-promoting role for oxidized lipids, we performed the present study in a wellcharacterized experimental model of restenosis known to involve not only SMC proliferation but also the deposition of lipids and lipoproteins and the accumulation of lipid-laden macrophages $(15-19)$.

\section{Methods}

The rabbit model of atherosclerosis combining femoral air desiccation with high cholesterol diet has been used previously in the evaluation of 
restenosis after angioplasty, and its advantages and disadvantages have been discussed (15-19). Male New Zealand White rabbits were used after approval by the Animal Research Committee of the Cleveland Clinic Foundation.

Atheroma induction in rabbit femoral artery by air desiccation. 3.54-kg animals were anesthetized by intramuscular injection of $5 \mathrm{mg} /$ kg xylazine (Rompun; Bayvet Division, Miles Laboratories Inc., West Haven, CT) and $35 \mathrm{mg} / \mathrm{kg}$ ketamine (Ketaset; Fort Dodge Laboratories, Inc., Fort Dodge, IA). Proximal bilateral femoral arteriotomies were performed, and proximal and distal ligatures were placed to isolate a segment of $\sim 1 \mathrm{~cm}$ which was cannulated with a 27 -gauge needle. A vent was made by needle puncture, and vascular injury was induced in the isolated segments by air infusion at a rate of $80 \mathrm{ml} / \mathrm{min}$ monitored by a flowmeter for $10 \mathrm{~min}$. The isolated segments were then flushed with saline and marked by metal clips in the surrounding tissue before removing the ligatures. Hemostasis was obtained by local pressure. Acetaminophen, $10 \mathrm{mg} / \mathrm{kg}$, was given orally for postoperative pain relief for $3 \mathrm{~d}$. Ampicillin, $50 \mathrm{mg} / \mathrm{kg}$, was given intramuscularly after the surgical procedure. The animals were placed on a $2 \%$ cholesterol and $6 \%$ peanut oil diet. $9 \mathrm{~d}$ after air desiccation, the diet of half of the animals was supplemented by alpha-tocopherol, $5 \mathrm{~g} / \mathrm{kg}$, while they remained on high cholesterol.

Femoral angioplasty. 4 wk after focal induction of the arterial lesions, 24 rabbits underwent bilateral balloon angioplasty under anesthesia as described above. After cutdown and isolation of the carotid artery, a $5 \mathrm{~F}$ introducer (Cordis Laboratories Inc., Miami, FL) was placed in the right common carotid artery, and a $120 \mathrm{U} / \mathrm{kg}$ heparin bolus was immediately injected intraarterially. An iliofemoral angiogram was performed via a $5 \mathrm{~F}$ Swan-Ganz catheter advanced to the aortoiliac bifurcation under the control of fluoroscopy using manual injection of 3-5 ml of renografin (Squibb Diagnostics, New Brunswick, NJ) and recorded both on a videotape system and a $35-\mathrm{mm}$ film by an image intensifier (Phillips Medical Systems, Shelton, CT). A 5-mm standard was placed at the level of the spine for correction of the magnification. A 2.0-3.0$\mathrm{mm}$ balloon catheter (Advanced Cardiovascular Systems, Santa Clara, CA), selected to match the size of the artery (balloon/artery diameter ratio, 1:1.3), was positioned across the stenosis, using fluoroscopy, the video cassette recording, and the previously placed metal clips. Standard angioplasty consisted of 3 inflations with $30-\mathrm{s}$ ramp to 6 atmospheres, then 6 atmospheres for $60 \mathrm{~s}$, each separated from the other by $60 \mathrm{~s}$. The procedure was performed in both femoral arteries at the lesion site. Post-angioplasty angiograms were performed $15 \mathrm{~min}$ after angioplasty and intraarterial injection of a 10-mg lidocaine bolus to minimize spasm (16). Blood samples were collected to measure cholesterol and alphatocopherol levels. The catheter was removed, the right carotid artery was ligated, and the wound was sutured.

After angioplasty, the high cholesterol diet was replaced by normal rabbit chow alone for the control animals and normal rabbit chow plus alpha-tocopherol, $5 \mathrm{~g} / \mathrm{kg}$, for the animals previously receiving alphatocopherol supplementation. An angiogram was performed $3 \mathrm{wk}$ after angioplasty under the same conditions as described above. After angiography, the distal aorta was ligated proximal to the end of the catheter, the animal was killed by an overdose of sodium pentobarbital intravenously, and the vessels were flushed with $10 \mathrm{ml}$ saline followed by in vivo fixation with $10 \%$ buffered formaldehyde solution infused over 30 min at $100 \mathrm{mmHg}$ at the aortoiliac bifurcation via the angiography catheter. A 3-cm segment of femoral artery was excised from both sides, including the site of the lesion identified by clips and a proximal length of the vessel. The tissue was stored in $10 \%$ buffered formaldehyde for morphometric measurements.

Angiographic measurements. The minimum luminal diameter (MLD) at the lesion site was measured from angiograms by two physicians using digital calipers. The two measurements were made independently and without knowledge of the group to which each animal belonged. The average of the two measurements was used for statistical comparisons.

Histological measurements. The femoral artery samples were embedded in paraffin and serial cross-sections were cut at 2-mm intervals from the proximal to the distal end and coded to identify their relative location to one another along the length of the lesion. Sections from duplicate slides were stained with trichrome.

Morphometric analysis was performed by the Laboratory of Vascular Diseases of the Ohio Sate University by personnel unaware of the group assignments of the lesions. Each histological section was scanned in full color using a digital scanner (model 78/99; Eikonix Corp., Bedford, MA) at a resolution of $1,024 \times 1,024$ pixels. Each pixel consisted of 3 8-bit values representing the amount of red, green, and blue at a particular position. Each full-color image was analyzed using an image processing system (IP 9527; Gould Inc., Glen Burnie, MD). Each image was displayed on a television monitor, and the external elastic lamina (EEL) and lumen boundary were manually identified. Custom software was used to compute the parameters of interest. Each full-color digital image was then archived onto tape. Parameters measured included crosssectional area of the lumen, maximum intima + media thickness, area of the intima + media, and perimeter of the EEL. Intima and media were measured together since the internal elastic lamina was often discontinuous $3 \mathrm{wk}$ after angioplasty, making distinctions between intima and media ambiguous.

Cell culture studies. Vascular SMC cultures were obtained from explants of rabbit aorta using procedures described previously $(20,21)$. Endothelium was removed enzymatically or by scraping, and an outer media and adventitia layer was peeled away from the inner media layer. The latter was minced into $\sim 1-\mathrm{mm}^{2}$ pieces with a scalpel, and the pieces were allowed to adhere to tissue culture plastic by partial drying (10-15 min). DME/F12 medium with $10 \%$ fetal bovine serum (FBS) was gently added, and the cultures were incubated at $37^{\circ} \mathrm{C}, 5 \% \mathrm{CO}_{2}$ in air. Cells migrated from explants in 5-12 d. When surrounded by outgrowth $\sim 10$ cells wide, the tissue pieces were removed and the cultures were refed. Cells were passed at confluence and plated for experimentation after several passages. Vascular SMC identification was by morphology typical of rabbit SMC under light microscopy.

To examine the effects of vitamin $\mathrm{E}$ on DNA synthesis in rabbit SMC, cells were plated into 24 -well plates at 20,000-25,000 cells/well in DME/F12 and 10\% FBS. Cells were rendered quiescent by replacing the media with serum-free DME/F12 for $3 \mathrm{~d}$. Quiescence was verified by the similarity between unstimulated cells and those given $4 \mathrm{mM}$ hydroxyurea to prevent entry into S phase (12). Cells were treated with vitamin E (dl-alpha-tocopherol; Sigma Immunochemicals, St. Louis, MO) $2 \mathrm{~h}$ before the addition of proliferative stimuli, either FBS or oxidized human LDL, isolated as previously described (22) and oxidatively modified by $\mathrm{CuSO}_{4}$ (23) or $\mathrm{FeSO}_{4}$ (12). Oxidized LDL preparations were used within a few days of oxidation or stored in aliquots at $-70^{\circ} \mathrm{C}$ for later use. Vitamin $\mathrm{E}$ was added to achieve $50 \mu \mathrm{M}$ final medium concentration using $<0.5 \%$ ethanol as a carrier. Control cultures (no added vitamin E) had solvent alone. $\left[{ }^{3} \mathrm{H}\right]$ Thymidine incorporation into DNA was determined for human foreskin fibroblasts (12) by adding $1 \mu \mathrm{Ci} / \mathrm{ml}$ methyl $\left[{ }^{3} \mathrm{H}\right]$ thymidine $(6.7 \mathrm{Ci} / \mathrm{mmol}$; ICN Biomedicals, Inc., Costa Mesa, CA) for the last $6 \mathrm{~h}$ of a 26-h exposure to stimuli. After removing radioactive medium, cells were washed with ice-cold 5\% trichloroacetic acid twice. Acid-precipitated materials were solubilized with $0.25 \mathrm{~N} \mathrm{NaOH}$, and radioactivity was assayed in a liquid scintillation counter (Tri-carb; Packard Instruments, Meriden, CT).

Oxidized LDL stimulation of SMC was examined in rabbit SMC analogous to the scheme described above by adding sublethal concentrations of oxidized human LDL, or native LDL as a control, to quiescent cultures of SMC and monitoring the subsequent incorporation of $\left[{ }^{3} \mathrm{H}\right]$ thymidine into DNA. These were performed using LDL oxidized by exposure to $\mathrm{FeSO}_{4}$ as well as $\mathrm{CuSO}_{4}$. In all cases, free and bound metal ions were depleted from the lipoprotein preparations by dialysis against $0.5 \mathrm{mM}$ EDTA in saline. The range of the levels of oxidation for such preparations as measured by thiobarbituric acid reactivity (12, 24 ) is typically equivalent to 4-12 nmol malondialdehyde (used as standard) per mg LDL cholesterol.

Lipoprotein and plasma cholesterol levels were measured with an enzymatic kit (Boehringer Mannheim Corp., Indianapolis, IN); plasma vitamin $\mathrm{E}$ was measured by HPLC (25). 


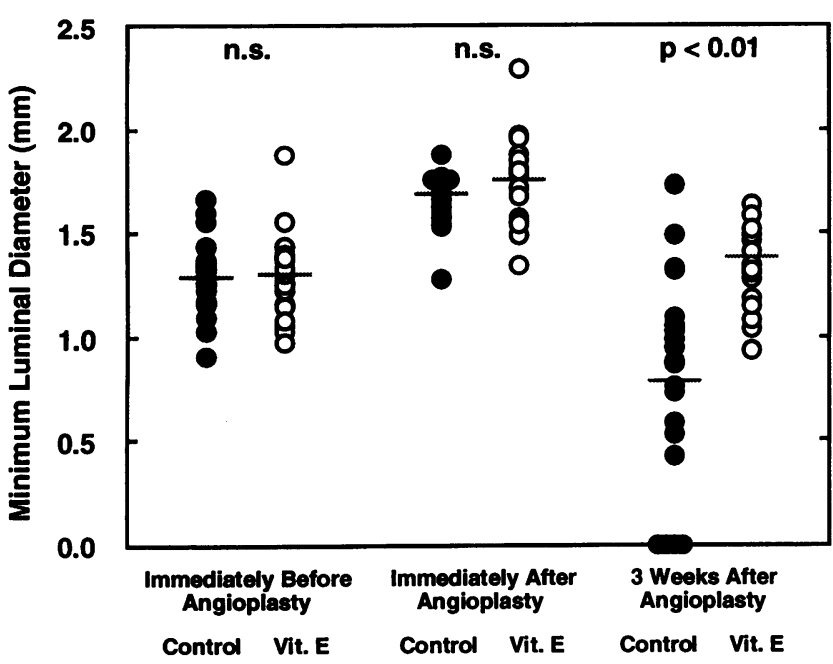

Figure 1. Angiographic evaluation of angioplasty and the effects of vitamin $\mathrm{E}$ on restenosis. Luminal diameters at the most occluded site of each femoral lesion were measured from angiograms by two observers and averaged to yield an MLD for each lesion before and immediately after angioplasty, as well as $3 \mathrm{wk}$ after. Open circles represent lesions of vitamin E-treated animals $(n=19)$; closed circles represent the untreated controls $(n=21)$. Horizontal lines in each data group are the means. n.s., no statistically significant difference between group means.

Statistical analysis. Unpaired Student's $t$ tests were performed to compare angiographic or histological data between the two groups. Paired $t$ tests were used to compare angiographic and biochemical data at different steps of the protocol. Histological parameters were examined by analysis of variance to test the influences of vitamin $E$ versus control treatment, left versus right femoral artery lesion responses, and the experimental set of animals (i.e., a first and a second group of animals were treated as described; the experiments were separated by several months time). These analyses indicated that the two lesions from each rabbit could be treated as independent data, that no correlation could be identified between the two arteries of animals in which two lesions were successful, and that there were no statistical differences between left and right lesions. Some animals had single lesions due to experimental problems that resulted in a deviation from the protocol or from severe stenosis of the air desiccation injury that precluded the use of the balloon. For example, lesions were excluded from the study because of occlusion before angioplasty, acute closure immediately after angioplasty, dissection resulting in aneurysm, or acute occlusive thrombosis at the site of angioplasty at termination (readily distinguished upon histologic evaluation). Additional statistical tests were performed to those shown in Results. These showed that restenosis in the vitamin E group was statistically significantly less than that in the control group even when $(a)$ animals that showed complete angiographic occlusion were omitted from the data pool; $(b)$ left and right lesions were averaged to yield single parameters for each animal; and $(c)$ the data from the two separate experiments were examined separately. Data displayed in Results show parameters from separate lesions from all animals in which the protocol was performed as specified in Methods.

\section{Results}

Fig. 1 displays the results of the angiographic assessment of the angioplasty and the subsequent restenosis. The data are presented in terms of the apparent luminal diameter at the most stenotic lesion site. Shown are the MLD for each lesion immediately before and after the balloon inflations and $3 \mathrm{wk}$ after the angioplasty for untreated animals and those animals orally treated with vitamin E. Fig. 1 indicates that there was no difference in the MLD between treated and untreated animals before angioplasty ( $1.34 \pm 0.26$ and $1.30 \pm 0.19$, respectively).

The angiographic data immediately after angioplasty compared with those before reveal the degree of increase or "improvement" in MLD. There were no significant differences between treated and untreated groups in the acute increases in lesion diameter in response to the angioplasty. The MLD increased an average of $0.40 \pm 0.28$ and $0.46 \pm 0.23 \mathrm{~mm}$ in the untreated and treated groups, respectively.

As others using this experimental model have reported previously, we found that a portion but not all of the untreated lesions restenosed to a level that would interfere substantially with blood flow (18); however, despite the substantial number of the untreated control lesions which did not severely restenose, the lesions of the vitamin E-treated group had statistically significantly larger MLD than the untreated control lesions ( $1.38 \pm 0.29$ vs $0.80 \pm 0.51 \mathrm{~mm}$, respectively, $P<0.01$ ).

Histological data were consistent with the angiographic data at 3 wk after angioplasty in that, as shown in Fig. 2, $A$ and $B$, the intima + media area of the treated group was significantly less than that of the untreated control group $(0.62 \pm 0.25$ vs $1.18 \pm 0.48 \mathrm{~mm}^{2}$, respectively, $P<0.0001$ ). Whereas the angiographic data in Fig. 1 represented each lesion by a single diameter at the most occluded site, the histologic data represented each lesion as the average value from four sites within the lesion, sampled at $\sim 2$-mm intervals. Fig. $2 A$ shows that plasma vitamin $E$ levels (the average of values measured at the time of angioplasty and $3 \mathrm{wk}$ after) were elevated in the vitamin Etreated group compared with the untreated group (9.6 \pm 4.6 vs $2.5 \pm 1.5$, respectively). This plot reveals that, analogous to the angiographic parameter in Fig. 1, a sizable portion of the untreated control lesions overlapped the range of the treated group for the histologically obtained parameters, e.g., the intima + media area of the lesions. Fig. $2 C$ indicates that the maximum wall thickness was also significantly less in the vitamin Etreated group.

As is typical with rabbits, the response of plasma cholesterol levels to a cholesterol- and oil-supplemented diet was highly variable. Fig. $3, A$ and $B$, reveal that the level of plasma cholesterol at the time of angioplasty (Fig. $3 A$ ) or the level 3 wk after (Fig. $3 B$ ) was not significantly different between the two groups; this regimen of vitamin $E$ treatment did not significantly lower plasma cholesterol. Fig. 3, $C$ and $D$, show that plasma cholesterol levels at either time did not predict differences in the intima + media area. In these figures the data for both groups of animals were arbitrarily separated into those with intima + media areas greater than or less than $1.0 \mathrm{~mm}^{2}$. The plasma cholesterols were not different between these two groups either at the time of angioplasty (Fig. $3 C$ ) or 3 wk later (Fig. $3 D$ ).

To examine whether constriction was responsible for the differences seen between the groups in this experiment (26), we compared the EEL circumference of the lesion sites for the two groups. Fig. $4 \mathrm{~A}$ shows the lack of a significant difference between the two groups. Another approach to discerning the relative roles of constriction and hyperplasia was also used. There is a theoretical relationship between the EEL circumference and the luminal area for a given average wall thickness. Examples of this relationship are shown in Fig. $4 B$ for average intima-media thicknesses of $100 \mu \mathrm{m}$ (upper curve) and $250 \mu \mathrm{m}$ 

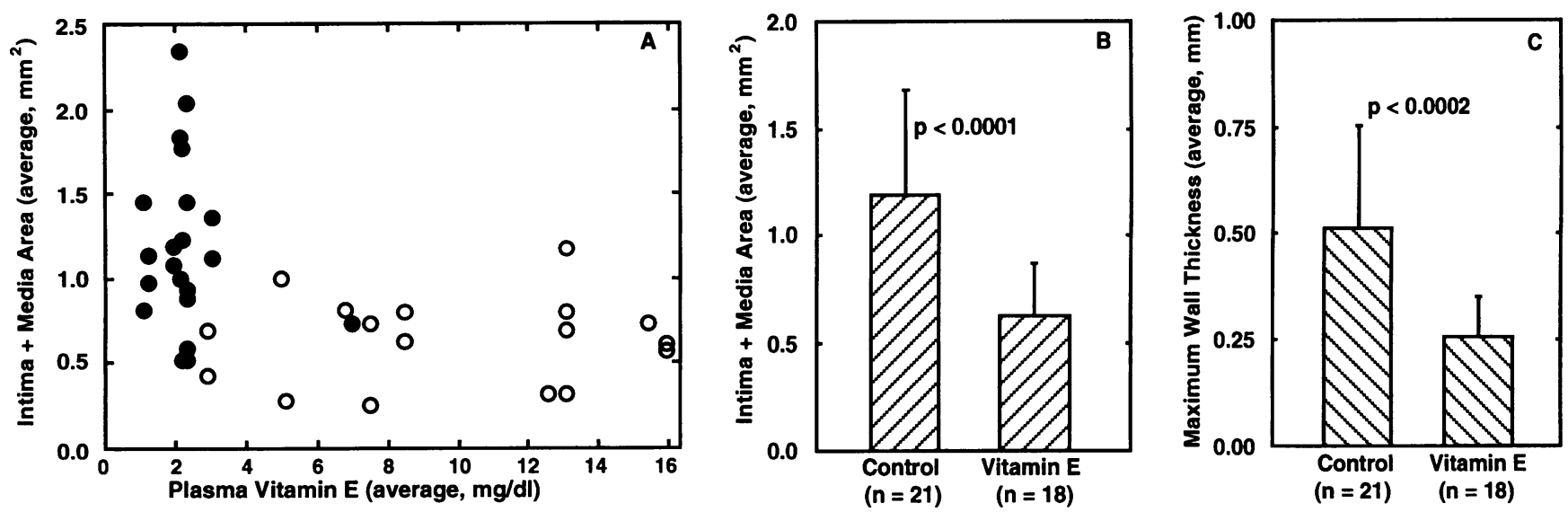

Figure 2. Histological evaluation of the effects of vitamin $\mathrm{E}$ treatment on restenosis. The area of the intima + media and the maximum thickness of a cross-section of the intima + media were obtained at multiple, equally spaced ( $\sim 2 \mathrm{~mm}$ ) sites (up to four) along each lesion. The parameters were averaged to yield a single value of intima + media area or maximum wall thickness for each lesion. $A$ shows the average intima + media area of individual lesions versus the plasma vitamin E level. Plasma vitamin E levels shown are the averages of the two values measured at the time of angioplasty and $3 \mathrm{wk}$ after. Open circles represent lesions of vitamin E-treated rabbits $(n=18)$; closed circles represent untreated control lesions $(n=21) . B$ and $C$ show the group means for $n$ lesions, standard deviations, and statistical differences between treated and untreated controls for the intima + media areas and the maximum wall thicknesses.

(lower curve). Data from each lesion from both groups are also plotted. Hyperplasia of the intima + media alone would reduce the luminal area for a given EEL size. Constriction without hyperplasia would have appeared as a reduction in luminal area approximately paralleling the theoretical curves. As shown in Fig. $4 B$, the reduced luminal areas of the untreated control lesions appear largely accounted for by hyperplasia. A sizable number of lesions from untreated animals exhibited reduced luminal area without a concomitant trend toward decreased EEL circumference in comparison with the treated group. This analysis does not indicate that constriction did not occur in selected vessels, but, taken together, Fig. $4, A$ and $B$, suggest that differences in constriction cannot explain the difference in restenosis between the treated and untreated groups.

To make initial appraisals of the mechanism by which SMC may proliferate more freely in the absence of additional vitamin $\mathrm{E}$ and that by which vitamin $\mathrm{E}$ treatment may have limited the restenotic response to balloon injury, two concepts were explored in rabbit SMC grown in culture. First, LDL, oxidatively modified in vitro, was incubated with rabbit aortic SMC at subtoxic levels to determine if such a preparation was capable of stimulating quiescent cells. Secondly, the cells were treated with vitamin $\mathrm{E}$ to determine if the antioxidant was capable of directly inhibiting stimulation by growth factors as has been suggested by others (13) or by oxidized LDL.

To determine whether lipid oxidation products are capable of stimulating rabbit vascular SMC to enter the cell cycle, oxidized LDL was added to cultures of quiescent SMC. Fig. 5 shows that oxidized LDL stimulated incorporation of labeled thymidine into DNA in cultured rabbit SMC. The stimulation was variable but significant and resulted in DNA synthesis levels up to $20-25 \%$ that of $10 \%$ serum. Results from other experiments (data not shown) have revealed that stimulation by oxidized $\mathrm{LDL}$ is observable whether $\mathrm{LDL}$ is oxidized using $\mathrm{FeSO}_{4}$ or $\mathrm{CuSO}_{4}$. We also asked whether vitamin $\mathrm{E}$ could alter SMC stimulation by oxidized LDL or serum mitogens. Fig. 6 shows that vitamin $\mathrm{E}$ did not inhibit DNA synthesis in rabbit SMC stimulated by serum (Fig. $6 A$ ) but that vitamin $\mathrm{E}$ potently inhibited DNA synthesis stimulated by oxidized LDL (Fig. $6 B)$.

\section{Discussion}

There is now compelling evidence that oxidized lipids and lipoproteins exist in atherosclerotic lesions (3-5). After balloon angioplasty there is likely an increased entry into the injury site of inflammatory cells capable of releasing reactive oxygen species and an increased entry of lipoprotein lipids from the plasma, the combination of which could result in the increased production of lipid oxidation products, which in turn could stimulate cell growth. As a step toward testing this idea, we examined the effects of pharmacological doses of the naturally occurring lipophilic antioxidant, alpha-tocopherol, on restenosis after angioplasty performed on a preexisting, lipid-containing lesion.

Vitamin E treatment reduced restenosis in this experimental model. The inhibition was statistically significant whether expressed angiographically, i.e., in terms of minimum luminal diameter (Fig. 1), or histologically, in terms of altered area of the intima + media, either at the site of maximum stenosis (not shown) or averaged over multiple sites (Fig. 2). The difference in restenotic response between treated and untreated animals was not a function of the plasma cholesterol level, either at the time of angioplasty or 3 wk later (Fig. 3).

The angiographic parameter, MLD, represents the lesion at its most stenotic site, whereas the histological parameter, intima + media area, offers a more representative view of the entire lesion since it is an average of cross-sections at up to four sites spaced approximately uniformly over the length of the lesion. Since MLD is a feature of the lumen, it could theoretically be reduced by a chronic constriction (26) as well as by hyperplasia. The histological data, however, allowed distinction between constriction and hyperplasia, and Fig. 4 indicates that chronic constriction was not a major factor in the differences between the groups. The difference appeared to be due in large part to hyperplasia.

Vitamin E treatment was begun in advance of angioplasty 

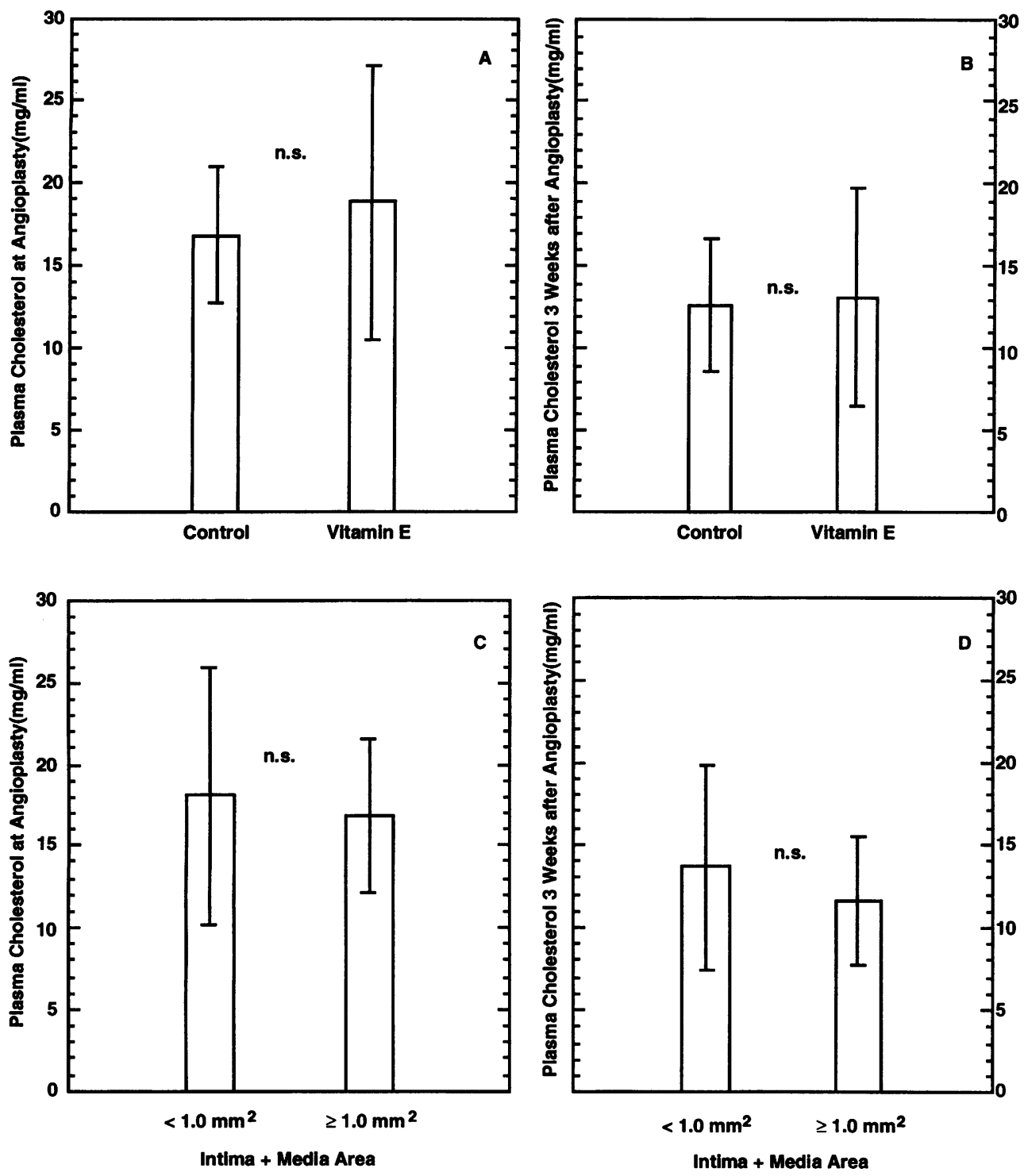

Figure 3. Lack of influence of plasma cholesterol levels on restenosis. $A$ and $B$ show that the cholesterol levels at the time of angioplasty and $3 \mathrm{wk}$ after angioplasty were not different between vitamin E-treated and control animals. In $C$ and $D$, data for intima + media area for all lesions are divided into more severely stenosed $\left(>1.0 \mathrm{~mm}^{2}\right)$ and less severely stenosed $\left(<1.0 \mathrm{~mm}^{2}\right)$ groups. The plasma cholesterol levels for these subgroups, either at the time of angioplasty $(C)$ or 3 wk later $(D)$, do not correlate with the severity of restenosis. Data shown are means and standard deviations.

to reach significantly elevated plasma levels before the balloon injury. This was successful in that the plasma vitamin $E$ levels at the time of angioplasty were markedly elevated in the treated over the untreated groups of animals $(13.0+6.4 \mathrm{mg} / \mathrm{dl}$ vs $2.9+1.6$, respectively). It was presumed that significant treatment time would also be required to enrich vitamin $E$ levels in tissue lipid pools. The angiographic data immediately before and after angioplasty shown in Fig. 1 indicate that the effects of vitamin $E$ treatment, which was begun $9 \mathrm{~d}$ after the initial air drying lesion and $19 \mathrm{~d}$ before angioplasty, did not alter the degree of stenosis due to this initial, desiccation-induced lesion or the acute response to dilation.

Controversy persists over the selection of restenosis models pertinent to humans. The model used in our study has both advantages and disadvantages. The initial lesion combines the participation of SMC proliferation, which is frequently an observed feature of the restenotic process in humans, with the accumulation of lipids and lipoproteins, which is a common attribute of human arterial lesions being treated by balloon angioplasty. Thus, in this model, as in its human counterpart, angioplasty is performed on a preexisting atherosclerotic lesion. The model has been used widely, is well-characterized, and has a known and somewhat predictable response to angioplasty (1519). In our hands (Figs. 1 and 2, for example) and in the studies of others (18), the untreated control group results in a mixed restenotic response. There was a significant number of vessels that by $3 \mathrm{wk}$ after angioplasty exhibited only limited luminal narrowing, as well as those which have markedly narrowed. While this characteristic puts an additional burden on statistical evaluation of a putative protective treatment, it bears a similarity to the experience in human coronary angioplasty.

However, there are recognized deficiencies in this model which prevent the extrapolation of findings to human conditions. The rapidly developed injury to the rabbit artery cannot be expected to mimic the features of a mature lesion developed in a human artery, which often exhibits calcification and fibrosis. Furthermore, the rapid rise to cholesterol levels of $1,000-2,000$ $\mathrm{mg} / \mathrm{dl}$ of predominantly beta-VLDL cholesterol, as seen in this model, is distinct from any occurrence in humans. Our results coupled with reports of the effects of other antioxidants in other models ( see below) suggest that oxidation may adversely influence restenosis. 

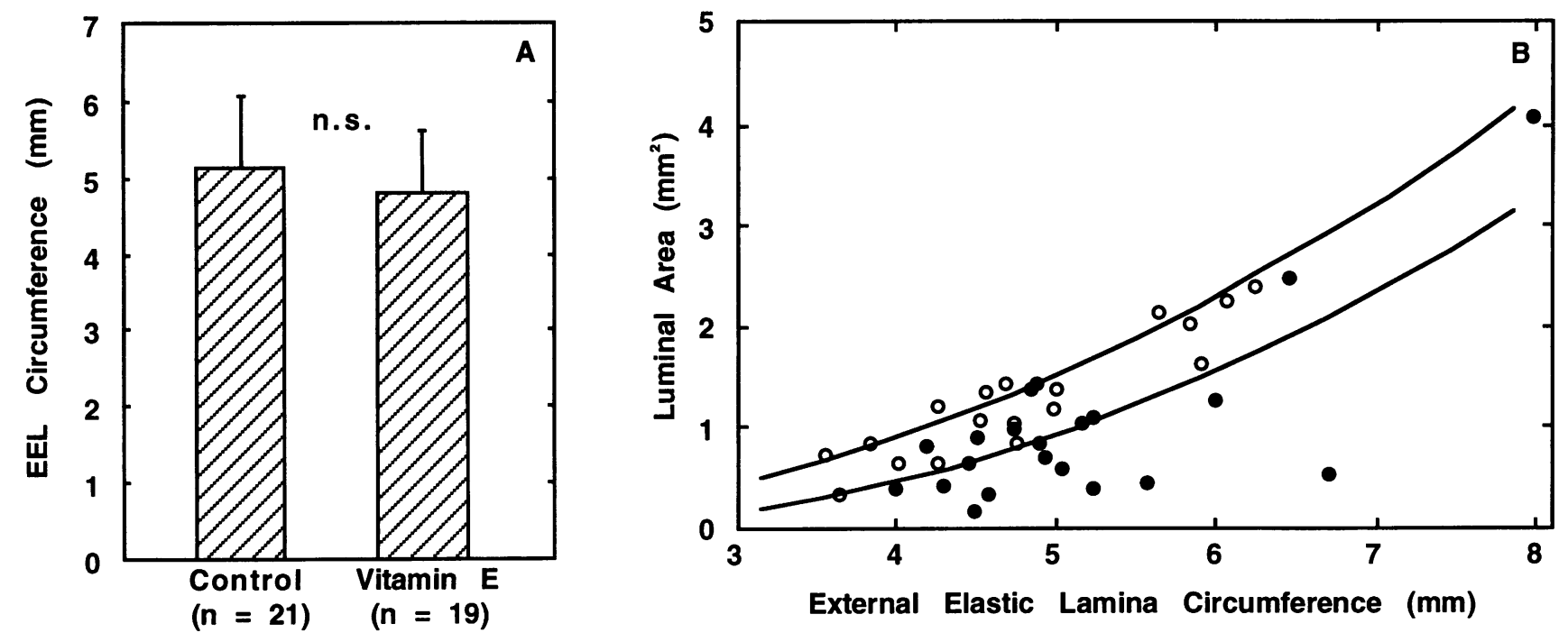

Figure 4. Lack of influence of vascular constriction on the difference in restenosis between vitamin E-treated and untreated animals. $A$ shows the group means and standard deviations for the EEL circumferences at the lesion site for $n$ lesions. The EEL circumference for each lesion was the average of multiple (up to four) measurements at equally spaced $(\sim 2 \mathrm{~mm}$ ) cross-sections along the lesion. $n . s$. indicates no statistically significant difference between the groups. In $B$ the theoretical relationship between EEL circumference and luminal area is given for average wall (intima + media) thicknesses of $100 \mu \mathrm{m}$ (upper line) and $250 \mu \mathrm{m}$ (lower line). Constriction alone would theoretically reduce the luminal area along a line approximately parallel to the two theoretical curves shown for a given wall thickness. The fact that the luminal areas for the untreated control lesions (closed circles) fall below the lower line (unlike the vitamin E-treated lesions; open circles) suggests that hyperplasia (reduced luminal area due to increased lesion thickness) rather than constriction could account for a major portion of the difference between the groups.

The rationale for the hypothesis that lipid oxidation may promote restenosis is based on several lines of experimental evidence. It has long been recognized that hydroperoxides formed during lipid and lipoprotein oxidation can damage or kill cells $(11,27)$. In contrast, as demonstrated by Murrell et al.

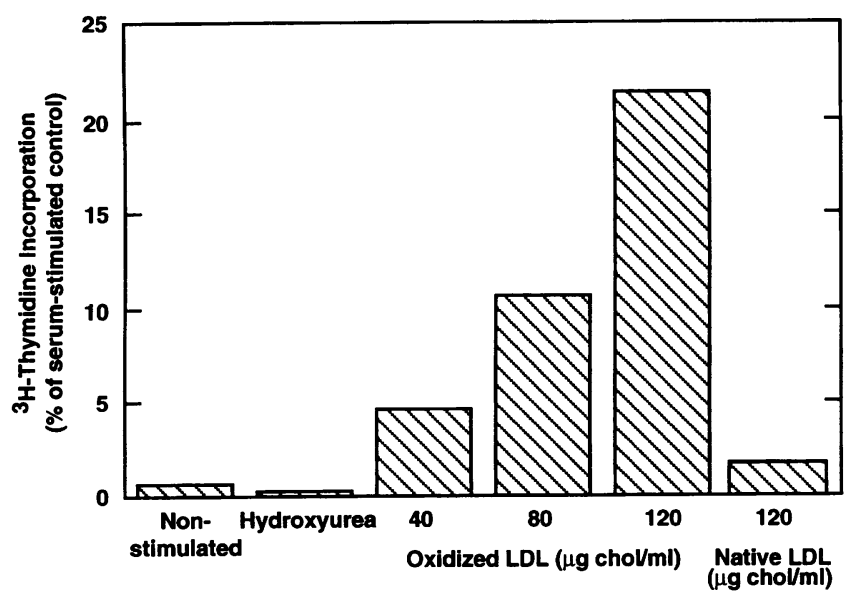

Figure 5. Incorporation of labeled thymidine into DNA in rabbit aortic SMC stimulated by oxidized LDL but not native LDL. Oxidized or native LDL was added to cultures of rabbit vascular SMC made quiescent by $72 \mathrm{~h}$ in serum-free medium. $\left[{ }^{3} \mathrm{H}\right]$ Thymidine incorporation into DNA was subsequently measured. Data are plotted as a percentage of stimulation by $10 \%$ FBS. For comparison, the nonstimulated (no lipoprotein, no serum) case is shown. The relative level of quiescence can be assessed by comparing the nonstimulated case to cells treated with hydroxyurea to block entry into $S$ phase. Data represent averages of duplicate wells. Stimulation by oxidized LDL was variable; data from this experiment are qualitatively representative of multiple experiments performed.
(8) and Burdon et al. (7), certain oxidants, including hydrogen peroxide, at subtoxic concentrations actually stimulate cell proliferation. Recently, it was also shown that hydrogen peroxide can stimulate DNA synthesis and increase cell number in cultures of vascular SMC (28). At sublethal levels, oxidized LDL has also been reported to stimulate vascular SMC movement (29) and proliferation (30) in culture. In contrast, oxidized LDL exerts a potent antimigratory effect, independent of cell injury, on endothelial cells ( 31 ). Thus, oxidants, including lipid hydroperoxides and oxidized LDL, which are likely to be present at the site of a balloon-injured arterial lesion, can stimulate SMC movement and proliferation by an unknown mechanism, while they may concomitantly inhibit endothelial repair.

It has also been demonstrated that lipid oxidation products can alter growth factor production in cells grown in culture, suggesting an indirect, autocrine or paracrine mechanism by which these agents could influence SMC proliferation (5). Oxidized LDL has been shown both to promote and inhibit production of various growth factors, depending on the type of target cell and the degree or mode of LDL oxidation (23, 32-37). Both LDL and oxidized LDL, but the latter more potently, have been shown to enhance PDGF-AA gene expression and PDGF receptor expression in vascular SMC (38). It is therefore theoretically possible that lipid oxidation products may indirectly potentiate the growth of SMC in a vascular injury site.

Various lipophilic antioxidants, alpha-tocopherol, probucol, or butylated hydroxytoluene, can block the oxidation of lipoproteins in vitro (39-41) and in vivo (42). We chose to use vitamin $\mathrm{E}$ since it is a naturally occurring antioxidant with relatively few known side effects even in pharmacological doses. Vitamin $\mathrm{E}$ has been demonstrated to alter vascular SMC growth in vitro. It has been reported to enhance the proliferation of vascular SMC (14) by inhibiting the formation of injurious oxidation products of free fatty acids and to inhibit the prolifera- 

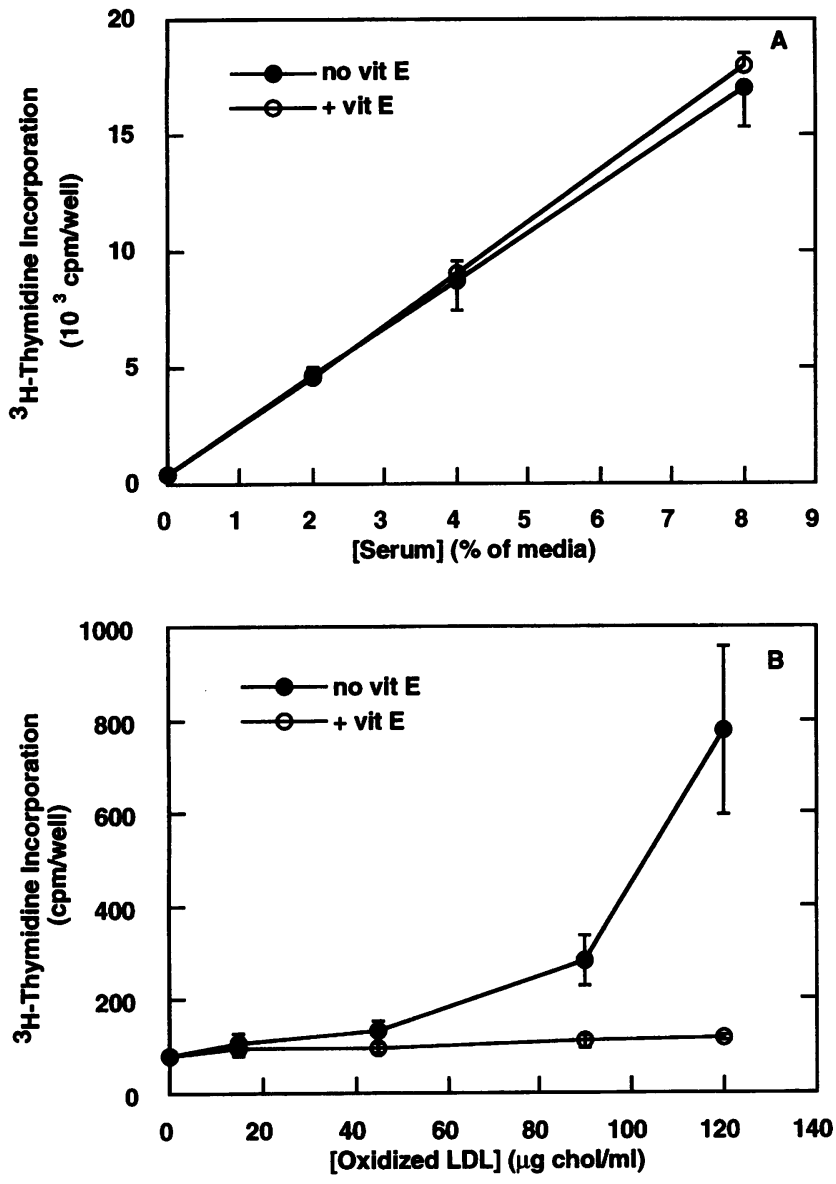

Figure 6. Effects of vitamin E on DNA synthesis in rabbit aortic SMC. Cultures of rabbit aortic SMC made quiescent by $72 \mathrm{~h}$ in serum-free media were stimulated to proliferate with various concentrations of FBS or oxidized LDL. Vitamin $\mathrm{E}$ was added to a final concentration of 50 $\mu \mathrm{M}$, as a 2 -h pretreatment in addition to concurrent incubation. Thymidine incorporation into DNA was quantified for the last $6 \mathrm{~h}$ of a 26-h incubation with stimuli. $A$ shows the lack of effect of vitamin $E$ on serum-stimulated entry of SMC into the cell cycle. $B$ shows effective inhibition by vitamin $E$ of labeled thymidine incorporation into DNA stimulated by oxidized LDL. Data represent means and standard deviations from three wells. The results from this experiment are representative of multiple experiments performed.

tion of SMC by inhibiting protein kinase $\mathrm{C}$ rather than by an antioxidant effect (13). We tested whether vitamin $\mathrm{E}$ could directly influence DNA synthesis in cultured rabbit vascular SMC after stimulation by oxidized LDL or by serum. Vitamin E failed to diminish the increased DNA synthesis (Fig. 6) when serum was added to cultures of rabbit aortic SMC; however, it markedly inhibited labeled thymidine incorporation into DNA in oxidized LDL-stimulated cells. Thus, it is possible that the vitamin $E$ effect we observe in vivo could be related either to the inhibition of the formation of proliferative oxidized lipids or lipoproteins, or to the direct inhibition by an unknown mechanism of proliferation stimulated by oxidants.

It was previously reported that alpha-tocopherol treatment of humans after angioplasty did not demonstrate statistically significant beneficial effects, although a trend toward an effect was noted (43). In contrast to the present study and others showing the benefit of lipophilic antioxidants (see below), the protocol of the cited study did not involve alpha-tocopherol treatment before angioplasty. The increase in lipid pools of dietary lipophilic antioxidants is generally slow, and the tissue response to angioplasty is believed to be determined within the early period after dilation, thus an optimal test of a vitamin $\mathrm{E}$ regimen may require pretreatment.

Our data are consistent with those of others reporting a beneficial effect of a variety of antioxidants after various forms of vascular injury. Probucol inhibited lesion formation after injury in a different atherosclerotic rabbit model (44), in a pig model of coronary angioplasty (45), and in a limited number of humans pretreated with the drug 2 wk before angioplasty (46). Ebselen, a potent indirect antioxidant by virtue of its capacity to break down a variety of lipid hydroperoxides, was also reported to be beneficial in a limited study of human restenosis after angioplasty (47). Butylated hydroxytoluene inhibited the response to arterial injury in hypercholesterolemic rabbits (48). Of interest, a combination of vitamins $C$ and $E$ was recently found to improve the response of pig coronary arteries to balloon injury compared with arteries of untreated animals, but the improvement was attributable to increased vessel size rather than decreased intimal area (49). It is too early to state definitively whether oxidant-induced proliferation contributes to restenosis, but the beneficial effects of pharmacological doses of vitamin $E$ in the current study suggest that this natural antioxidant should be tested further for effectiveness in other animal models.

\section{Acknowledgments}

The authors wish to thank Dr. Augusto Villa for assistance with angiographic measurements, Ms. Joy Brown for assistance with histological studies, Mr. Edward Herderick for assistance with imaging, Dr. Paul DiCorleto for cultured cells, and Dr. Frederick Van Lente for vitamin E assays.

These studies were supported by a grant from the National Institutes of Health (HL-47852 to G. M. Chisolm) and a fellowship from the American Heart Association, Northeast Ohio Affiliate (to A. M. Lafont).

\section{References}

1. Liu, M. W., G. S. Roubin, and S. B. King. 1989. Restenosis after coronary angioplasty: potential biologic determinants and role of intimal hyperplasia. Circulation. 79:1374-1387.

2. Gravanis, M. B., and G. S. Roubin. 1989. Histopathologic phenomena at the site of percutaneous transluminal coronary angioplasty: the problem of restenosis. Hum. Pathol. 20:477-485.

3. Steinbrecher, U. P., H. Zhang, and M. Lougheed. 1990. Role of oxidatively modified LDL in atherosclerosis. Free Radical Biol. \& Med. 9:155-168.

4. Steinberg, D., S. Parthasarathy, T. E. Carew, J. C. Khoo, and J. L. Witztum. 1989. Beyond cholesterol. Modifications of low-density lipoprotein that increase its atherogenicity. N. Engl. J. Med. 320:915-924.

5. Chisolm, G. M. 1992. The oxidation of lipoproteins: implications for atherosclerosis. In Mechanisms and Consequences of Oxidative Damage. L. Spatz and A. D. Bloom, editors. Oxford University Press, New York. 78-106.

6. Ramirez, C. A., C. K. Colton, K. A. Smith, M. B. Stemerman, and R. S. Lees. 1984. Transport of ${ }^{125} \mathrm{I}$-albumin across normal and deendothelialized rabbit thoracic aorta in vivo. Arteriosclerosis. 4:283-291.

7. Burdon, R. H., V. Gill, and C. Rice-Evans. 1989. Cell proliferation and oxidative stress. Free Radical Research Communications. 7:149-159.

8. Murrell, G. A., M. J. Francis, and L. Bromley. 1990. Modulation of fibroblast proliferation by oxygen free radicals. Biochem. J. 265:659-665.

9. Quigley, P. J., M. A. Hlatky, T. Hinohara, D. S. Rendall, J. A. Perez, H. R. Phillips, R. M. Califf, and R. S. Stack. 1989. Repeat percutaneous transluminal coronary angioplasty and predictors of recurrent restenosis. Am. J. Cardiol. 63:409-413. 
10. Chisolm, G. M., K. C. Irwin, and M. S. Penn. 1992. Lipoprotein oxidation and lipoprotein-induced cell injury in diabetes. Diabetes. 41 (Suppl. 2):61-66.

11. Chisolm, G. M. 1991. Cytotoxicity of oxidized lipoproteins. Curr. Opin. Lipidol. 2:311-316.

12. Kosugi, K., D. W. Morel, P. E. DiCorleto, and G. M. Chisolm. 1987. Toxicity of oxidized low-density lipoprotein to cultured fibroblasts is selective for S phase of the cell cycle. J. Cell. Physiol. 130:311-320.

13. Boscoboinik, D., A. Szewczyk, C. Hensey, and A. Azzi. 1991. Inhibition of cell proliferation by $\alpha$-tocopherol. Role of protein kinase C. J. Biol. Chem. 266:6188-6194.

14. Lindsey, J. A., H. F. Zhang, H. Kaseki, N. Morisaki, T. Sata, and D. G. Cornwell. 1985. Fatty acid metabolism and cell proliferation. VII. Antioxidants effects of tocopherols and their quinones. Lipids. 20:151-157.

15. LeVeen, R. F., G. L. Wolf, and T. G. Villanueva. 1982. New rabbi atherosclerosis model for the investigation of transluminal angioplasty. Invest. Radiol. 17:470-475.

16. Sarembock, I. J., P. J. LaVeau, S. L. Sigal, I. Timms, J. Sussman, C Haudenschild, and M. D. Ezekowitz. 1989. Influence of inflation pressure and balloon size on the development of intimal hyperplasia after balloon angioplasty Circulation. 80:1029-1040.

17. Sarembock, I. J., S. D. Gertz, L. W. Gimple, R. M. Owen, E. R. Powers, and W. B. Roberts. 1991. Effectiveness of recombinant desulphatohirudin in reducing restenosis after balloon angioplasty of atherosclerotic femoral arteries in rabbits. Circulation. 84:232-243.

18. McNamara, C. A., I. J. Sarembock, L. W. Gimple, J. W. Fenton, S. R. Coughiin, and G. K. Owens. 1993. Thrombin stimulates proliferation of cultured rat aortic smooth muscle cells by a proteolytically activated receptor. J. Clin. Invest. 91:94-98.

19. Ragosta, M., L. W. Gimple, H. L. Haber, C. T. Dunwiddie, G. P. Vlasuk E. R. Powers, and I. J. Sarembock. 1992. Effectiveness of specific factor Xa inhibition on restenosis following balloon angioplasty in rabbits. J. Am. Coll. Cardiol. 19:164a.(Abstr.)

20. Ross, R. 1971. The smooth muscle cell II. Growth of smooth muscle in culture and formation of elastic fibers. J. Cell Biol. 50:172-186.

21. Morel, D. W., P. E. DiCorleto, and G. M. Chisolm. 1984. Endothelial and smooth muscle cells alter low density lipoprotein in vitro by free radical oxidation. Arteriosclerosis. 4:357-364.

22. Morel, D. W., P. E. DiCorleto, and G. M. Chisolm. 1986. Modulation of endotoxin-induced endothelial cell toxicity by low density lipoprotein. Lab. Invest. $55: 419-426$.

23. Hamilton, T. A., G. P. Ma, and G. M. Chisolm. 1990. Oxidized low density lipoprotein suppresses the expression of tumor necrosis factor-alpha mRNA in stimulated murine peritoneal macrophages. J. Immunol. 144:2343-2350.

24. Schuh, J., G. F. Fairclough, and R. H. Haschemeyer. 1978. Oxygenmediated heterogeneity of apo-low-density lipoprotein. Proc. Natl. Acad. Sci. USA. 75:3173-3177.

25. Bieri, J. G., T. Tolliver, and G. L. Catignani. 1979. Simultaneous determination of alpha-tocopherol and retinol in plasma or red cells by high pressure liquid chromatography. Am. J. Clin. Nutr. 32:2143-2149.

26. Lafont, A. M., G. M. Chisolm, P. L. Whitlow, M. Goormastic, and J. F. Cornhill. 1994. Post-angioplasty restenosis in the atherosclerotic rabbit: proliferative response or chronic constriction? Circulation. 88:I-521.(Abstr.)

27. Farber, J. L., M. E. Kyle, and J. B. Coleman. 1990. Mechanisms of cell injury by activated oxygen species. Lab. Invest. 62:670-679.

28. Rao, G. N., and B. C. Berk. 1992. Active oxygen species stimulate vascular smooth muscle cell growth and protooncogene expression. Circ. Res. 70:593599.

29. Autio, I., O. Jaakkola, T. Solakivi, and T. Nikkari. 1990. Oxidized lowdensity lipoprotein is chemotactic for arterial smooth muscle cells in culture. FEBS (Fed. Eur. Biochem. Soc.) Lett. 277:247-249.

30. Chatterjee, S. 1992. Role of oxidized human plasma low density lipoproteins in atherosclerosis: effects on smooth muscle cell proliferation. Mol. Cell. Biochem. 111:143-147.

31. Murugesan, G., G. M. Chisolm, and P. L. Fox. 1993. Oxidized low density lipoprotein inhibits the migration of aortic endothelial cells in vitro. J. Cell Biol. 120:1011-1019.

32. Fox, P. L., G. M. Chisolm, and P. E. DiCorleto. 1987. Lipoprotein mediated inhibition of endothelial cell production of platelet-derived growth factorlike proteins depends on free radical lipid peroxidation. J. Biol. Chem. 262:60466054.

33. Malden, L. T., A. Chait, E. W. Raines, and R. Ross. 1991. The influence of oxidatively modified low density lipoproteins on expression of platelet-derived growth factor by human monocyte-derived macrophages. J. Biol. Chem. 266:13901-13907.

34. Fong, L. G., T. A. T. Fong, and A. D. Cooper. 1991. Inhibition of lipopolysaccharide-induced interleukin-1 $\beta$ mRNA expression in mouse macrophages by oxidized low density lipoprotein. J. Lipid Res. 32:1899-1910.

35. Boulanger, C. M., F. C. Tanner, M.-L. Béa, A. W. A. Hahn, A. Werner, and T. F. Lüscher. 1992. Oxidized low density lipoproteins induce mRNA expression and release of endothelin from human and porcine endothelium. Circ. Res. 70:1191-1197.

36. Jougasaki, M., K. Kugiyama, Y. Saito, K. Nakao, H. Imura, and H. Yasue. 1992. Suppression of endothelin-1 secretion by lysophosphatidylcholine in oxidized low density lipoprotein in cultured vascular endothelial cells. Circ. Res. 71:614-619.

37. Rajavashisth, T. B., A. Andalibi, M. C. Territo, J. A. Berliner, M. Navab, A. M. Fogelman, and A. J. Lusis. 1990. Induction of endothelial cell expression of granulocyte and macrophage colony-stimulating factors by modified low-density lipoproteins. Nature (Lond.). 344:254-257.

38. Stiko-Rahm, A., A. Hultgardh-Nilsson, J. Regnstrom, A. Hamsten, and J. Nilsson. 1992. Native and oxidized LDL enhances production of PDGF AA and the surface expression of PDGF receptors in cultured human smooth muscle cells. Arterioscler. Thromb. 12:1099-1109.

39. Morel, D. W., J. R. Hessler, and G. M. Chisolm. 1983. Low density lipoprotein cytotoxicity induced by free radical peroxidation of lipid. J. Lipid Res. 24:1070-1076.

40. Steinbrecher, U. P., S. Parthasarathy, D. S. Leake, J. L. Witztum, and D. Steinberg. 1984. Modification of low density lipoprotein by endothelial cells involves lipid peroxidation and degradation of low density lipoprotein phospholipids. Proc. Natl. Acad. Sci. USA. 81:3883-3887.

41. Heinecke, J. W., H. Rosen, and A. Chait. 1984. Iron and copper promote modification of low density lipoprotein by human arterial smooth muscle cells in culture. J. Clin. Invest. 74:1890-1894.

42. Morel, D. W., and G. M. Chisolm. 1989. Antioxidant treatment of diabetic rats inhibits lipoprotein oxidation and cytotoxicity. J. Lipid Res. 30:1827-1834.

43. DeMaio, S. J., S. B. King, N. J. Lembo, G. S. Roubin, J. A. Hearn, H. N. Bhagavan, and D. S. Sgoutas. 1992. Vitamin E supplementation, plasma lipids and incidence of restenosis after percutaneous transluminal coronary angioplasty (PTCA). J. Am. Coll. Nutr. 11:68-73.

44. Ferns, G. A. A., L. Forster, A. Stewart-Lee, M. Konneh, J. NouroozZadeh, and E. E. Änggård. 1992. Probucol inhibits neointimal thickening and macrophage accumulation after balloon injury in the cholesterol-fed rabbit. Proc. Natl. Acad. Sci. USA. 89:11312-11316.

45. Schneider, J. E., B. C. Berk, M. B. Gravanis, E. C. Santoian, G. D. Cipolla N. Tarazona, B. Lassegue, and S. B. King. 1993. Probucol decreases neointimal formation in a swine model of coronary artery balloon injury. A possible role for antioxidants in restenosis. Circulation. 88:628-637.

46. Lee, Y. J., H. Yamaguchi, H. Daida, H. Yokol, H. Miyano, J. Takaya, H. Sakurai, and A. Noma. 1991. PTCA: pharmacological interventions to modify restenosis. Circulation. 84:II-298.( Abstr.)

47. Hirayama, A., S. Nanto, T. Ohara, K. Nishida, Y. Okuyama, and K. Kodama. 1992. Preventive effect on restenosis after PTCA by Ebselen: a newly synthesized anti-inflammatory agent. J. Am. Coll. Cardiol. 19:259a.(Abstr.)

48. Freyschuss, A., A. Stiko-Rahm, J. Swedenborg, P. Henriksson, I. Björkhem, L. Berglund, and J. Nilsson. 1993. Antioxidant treatment inhibits the development of intimal thickening after balloon injury of the aorta in hypercholesterolemic rabbits. J. Clin. Invest. 91:1282-1288.

49. Nunes, G. L., D. S. Sgoutas, S. R. Sigman, B. Britt, M. B. Gravanis, S. B. King III, and B. C. Berk. 1993. Vitamins C and E improve the response to coronary balloon injury in the pig: effect of vascular remodeling. Circulation. 88:I-372a.(Abstr.) 